\title{
CREDIT RISK MODELLING FOR INDIAN DEBT SECURITIES USING MACHINE LEARNING
}

\author{
Charumathi Balakrishnan* and Mangaiyarkarasi Thiagarajan** \\ * Corresponding author. Department of Management Studies, School of Management, Pondicherry \\ University, India. Email: profcharu@gmail.com \\ **Department of Management Studies, Vels Institute of Science, Technology \& Advanced Studies, India. \\ Email: mangai.kalai@gmail.com
}

\begin{abstract}
We develop a new credit risk model for Indian debt securities rated by major credit rating agencies in India using the ordinal logistic regression (OLR). The robustness of the model is tested by comparing it with classical models available for ratings prediction. We improved the model's accuracy by using machine learning techniques, such as the artificial neural networks (ANN), support vector machines (SVM) and random forest (RF). We found that the accuracy of our model has improved from $68 \%$ using OLR to $82 \%$ when using ANN and above $90 \%$ when using SVM and RF.
\end{abstract}

Keywords: Credit risk modelling; Credit rating prediction; Emerging market score model; Machine learning; Indian debt market.

JEL Classifications: G24; G32; G33.

\section{Article history:}

Received : September 26, 2020

Revised : December 04, 2020

Accepted : December 11, 2020

Available Online: January 31, 2021

https://doi.org/10.21098/bemp.v24i0.1401 


\section{INTRODUCTION}

Corporate debt market in India increased from 52 billion USD in 2013-14 to 92 billion USD in 2018-19 and is crucial in meeting the financing requirements of the industrial and infrastructure sectors. The Government and regulators have been taking measures for the development of the debt market. In this context, the role of rating agencies in disseminating information about credit risk of debt issuers in the form a symbolic indicators (eg. AAA, AA, A, BBB, BB, B, C, D) remains crucial. Rating as a measure of credit risk is being used in various legislations of national and international context (Basel III, 2017) and insurance companies, pension funds, broker-dealers face rating-based investment limitations (Benmelech \& Dlugosz, 2009).

Given the importance of ratings, it has become an important tool and is widely used in regulating capital market (Partnoy, 2009). Increased usage of credit rating and oligopolistic competition had led to credit rating crisis (Gerardi, Sherlund, Lehnert, \& Willen, 2008), which resulted in global economic slowdown and bankruptcy of several prominent banks. After the crisis, rating agencies had gained much negative attention leading countries to reduce their reliance on credit ratings. There had also been instances in India where highly rated debt securities were suddenly downgraded and rating agencies were held accountable for poor rating quality (Palande, 2015; Pillay, 2015). These factors had forced investors to measure credit risk through independent methodologies and the key question is whether credit risk can be modelled using publicly available data. Advancement of new computational techniques resulted in using machine learning for credit risk classification. Another pertinent question is whether these methods improve the prediction accuracy of the credit risk model.

There is a large literature on default prediction, mostly focussed on developed economies (see Beaver, 1966; Deakin, 1972 for univariate studies). Multivariate studies (Altman, 1968; Pinches \& Mingo, 1973; Ang \& Patel, 1974; Kaplan \& Urwitz, 1979; Ho \& Rao, 1993; Duvall \& R.S.Rathinasamy, 1993; Altman, Hartzel, \& Peck, 1998; Altman, 2005) have identified financial variables as the strongest indicators of default and their ability to classify with greater accuracy. Disadvantages of multivariate regression led to the construction of multivariate probit models (Kaplan \& Urwitz, 1979; Gentry, Whitford, \& Newbold, 1985; Ho \& Rao, 1993) and logistic regressions (Alifiah \& Tahir, 2018). Though several studies focus on bankruptcy prediction, only sporadic studies are available on rating class prediction (Horrigan, 1966; Kaplan \& Urwitz, 1979; Altman, 2005).

In the context of Asia in general and India in particular, very few studies explore default prediction (Bandyopadhyay, 2006; Pradhan, 2014). There is a dearth of research studies on credit rating agencies and their rating methodology for India. We develop a credit risk model for rating Indian corporate debt using financial, industry and rating data. In our study, apart from the financial ratios, we intend to use the index of industrial production (IIP) as a measure of performance of industries. Studies have shown that advanced methods are successful in bankruptcy prediction/classification in the context of developed economies (Back, Laitinen, \& Sere, 1996; Zurada, Foster, \& Ward, 2002; Huang, Chen, Hsua, Chen, \& Wu, 2004; Yim \& Mitchell, 2005; Iturriaga \& Sanz, 2015; Gante, Gerardo, \& Tanguilig, 2015; Ibourk \& Aazzab, 2016). None of the studies have considered 
developing economies. We intend to utilize machine learning techniques in our model to improve the rating prediction.

The results of our empirical analysis show that the Ordinal Logistic Regression (OLR) model is better than other available rating models for rating Indian corporate debt. Prediction accuracy of the model improves from $68 \%$ using OLR to $82 \%$ using Artificial Neural Networks (ANN). The accuracy improves to above 90\% when implemented using advanced techniques like Random Forest (RF) and Support Vector Machines (SVM).

We make the following contributions: First, a new rating model is developed for predicting credit risk of corporate debt securities in India using nine predictor variables for the 2012-13 to 2016-17 period. We differentiate our study from the existing literature by adding an industry variable (the index of industrial production) in addition to firm level variables. Robustness of the model is checked by comparing the new model with classical models (Horrigan, 1966; Kaplan \& Urwitz, 1979; Altman, 2005) developed for rating prediction. Second, we show the efficacy of advanced Machine Learning (ML) techniques for rating class prediction for debt securities in India. Third, the stress testing of the new model is done by using a new sample covering 2017-18. Finally, our model serves as an unbiased (developed by independent researchers) rating prediction model for Indian debt which can be used by financial analysts and institutional investors. In view of the socio-cultural and demographic differences in credit culture between emerging economies and developed economies, our study sheds new insights and provides a guide to developing credit risk models for emerging economies.

In the rest of the paper, Section II covers methodology, Section III elaborates on data and results, and Section IV provides scope for future research and conclusion.

\section{METHODOLOGY}

A. Ordinal Logistic Regression

Our credit risk model takes the following form:

$$
\operatorname{logit}(P(Y \leq j))=\propto_{j}+\sum \beta_{i} X_{i}
$$

where $j$ is the ordered response with five levels and $i$ corresponds to independent variables. We use nine predictor variables selected from the literature for the development of the model. The logit function in Equation (1) describes the effect of independent variables on the ordinal response variable. The OLR was preferred since rating class represents an ordinal variable with AAA being the lowest risk class and $\mathrm{D}$ being the highest risk class. The model is evaluated by comparing it with other classical credit risk models like emerging market score model, the Horrigan model and the Kaplan-Urwitz model.

The measures employed for evaluating the ordinal regression model include zero and residual deviance, Akaike information criteria (AIC), the Log Likelihood, and Pseudo- $R^{2}{ }^{1}$ Deviance represents goodness of fit of the ordinal

1 Evaluation measures for the ordinal regression model were obtained here. https://www.hackerearth. com/practice/machine-learning/machine-learning-algorithms/logistic-regression-analysis-r/tutorial/ 
model and the lesser the deviance, the greater is the fit of the model. Null deviance is calculated from the model with no predictors and residual deviance is calculated from the model with all the predictors. The AIC is considered as a counterpart of $R^{2}$ which is an important indicator of model fit. The objective of the log likelihood function is to find the set of parameters that maximize its value. Measures of Pseudo $R^{2}$ used in assessing the ordinal model fit are McFadden (1974), Cox and Snell (1989) and Nagelkerke (1991). Further, multicollinearity between predictors of the model was checked using the variance inflation factor and the eigen values (James, Witten, Hastie, \& Tibshirani, 2013).

\section{B. Machine Learning}

Using the independent variables of the model, we use ML techniques to predict the rating class of securities into AAA, AA, A, B and D (multi-class classification). The ML techniques such as ANN, SVM and RF are implemented and compared with OLR results of the new model as well as classical models.

The ML is a subset of artificial intelligence and is successfully used in distress prediction, which is a two-class classification used to distinguish between bankrupt and non-bankrupt companies (Emerson et al., 2019). Inspired by the neurophysiological functions of the brain, ANN uses Multi-Layer Perceptron (MLP) to imitate the functions of the biological neuron (McCulloch \& Pitts, 1943). A standard MLP also known as feed forward neural networks has three layers, namely input layer with n co-variates, hidden layer, and an output layer (Günther $\&$ Fritsch, 2010). The output function with $j$ hidden neurons is given by $O(x)$.

$$
O(x)=f\left(w_{0}+\sum_{j=1}^{J} w_{j} . f\left(w_{0 j}+\sum_{i=0}^{n} w_{i j} x_{i}\right)\right)
$$

where, $w_{0}$ is the intercept of the output neuron and $w_{0 j}$ is the intercept of the $j$ th hidden neuron. $w_{j}$ is the synaptic weight starting at the $j t h$ hidden neuron and leading to the output neuron. The vector of all synaptic weights corresponding to $j$ th hidden neuron is given by $w_{j}=\left(w_{1 j} \ldots w_{n j}\right)$ and the vector of all input covariates are given by $x=\left(x_{1} \ldots x_{n}\right)$.

Support-vector network is a new learning machine which maps the input vectors into a high dimensional feature space, and the linear decision surface thus constructed has high generalisation ability (Cortes \& Vapnik, 1995). SVM is facilitated by the Kernel function namely linear, radial basis, polynomial and sigmoid (Yuan \& Chu, 2007) and in this study, the best one was found to be the radial basis function. The radial basis kernel function is given by the following equation:

$$
K\left(X, X^{\prime}\right)=\exp \left(-\sigma\left\|X-X^{\prime}\right\|^{2}\right)
$$

where $X$ is the unknown vector and $X^{\prime}$ is the image of a support vector in input space. Based on the function given in Equation (3), SVM determines the hyperplane which classifies the training samples. 
$\mathrm{RF}$ is the type of decision tree model which uses the combination of tree predictors, such that each tree depends on the values of the independently sampled random vector (Breiman, 2001). The RF provides robust results even in the presence of outliers and noise (Yeh, Chi, \& Lin, 2014). RF grows many trees by classifying new objects from an input vector and each tree gives classification, and the forest chooses the class with maximum votes.

These steps are followed for training the model using various ML techniques:

1. Data are prepared by checking for missing values. Missing values, if any, are removed from the sample. The data are normalized using the min-max normalization technique, which allows us to preserve the original distribution of scores except for a scaling factor. This process transforms all the scores into a common range $[0,1]$. With normalization, learning is faster and can lead to faster convergence.

2. The sample dataset is divided into a train dataset and a test dataset randomly and a $80 \%$ split is used for training dataset while the remaining $20 \%$ is used for testing. Training dataset is the actual dataset used to train the model. Test dataset is used to evaluate the model fit.

3. Multiple iterations are done with different training sets and by adjusting the number of hidden layers. Errors and prediction accuracy for each rating model are tabulated and the rating models which have the highest prediction accuracy and lowest error are selected.

4. Selected models are evaluated using the test dataset. The best model is chosen based on the condition that the prediction accuracy of the test dataset approximately equals to the prediction accuracy of the training dataset.

5. The models are further validated in a new sample of rating data belonging to year 2017-18.

The predictive ability of all the models is tested using the confusion matrix (Kohavi \& Provost, 1998), which is a cross tabulation of actual rating and predicted rating. Performance metrics used include the accuracy rate, the F-score, sensitivity and specificity as given in Equations (4)-(7). The accuracy rate is calculated by dividing the number of accurate classifications with the total number of samples in the validation set (Labatut \& Cherifi, 2011). The F-score measure corresponds to the harmonic mean of sensitivity and specificity. Sensitivity and specificity are also referred to as the true positive rate (TPR) and true negative rate (TNR), respectively.

$$
\begin{aligned}
& \text { Accuracy rate }=\frac{(T P+T N)}{(T P+T N+F P+F N)} \\
& \text { F-score }=\frac{2 * T P}{(2 * T P+F P+F N)} \\
& \text { Sensitivity }(\mathrm{TPR})=\frac{T P}{T P+F N} \\
& \text { Specificity }(\mathrm{TNR})=\frac{T N}{T N+F P}
\end{aligned}
$$


where True Positive (TP) and False Positive (FP) are instances correctly and incorrectly classified; and True Negatives (TN) and False Negatives (FN) are instances correctly and incorrectly not classified. The models are implemented in the R statistical software package using MASS, Neuralnet and Mctest library.

\section{DATA AND RESULTS}

A. Data and Sample

Using secondary data, this empirical study attempts to predict the rating class of long term debt securities (debentures and bonds) issued by Indian manufacturing companies which were rated by any one of the four major CRAs in India, namely, Credit Rating and Information Services Ltd. (CRISIL), Credit Analysis and Research Ltd. (CARE), Investment information and Credit Rating Agency Ltd. (ICRA), IndiaRatings and Research Ltd. from 2012-13 to 2017-18. These four rating agencies hold more than $80 \%$ market share in India and the rating given by them were included in the study. Following the subprime crisis, there were many regulatory changes for Indian rating agencies and the study period was based on two reasons. There was sharp growth in Indian debt market during that period and in 2011 rating scales were standardised, which means that rating symbols hold the same meaning across all rating agencies (SEBI, 2011).

The rating issued by manufacturing companies was chosen for the study because the sector had grown by more than $7 \%$ a year over the last three decades and represents $20 \%$ of India's GDP (CRISIL, 2018). Moreover, India ranked $30^{\text {th }}$ on the Global Manufacturing Index published by the World Economic Forum and was the fifth largest manufacturer in the world with the total value of USD 420 billion. There was higher demand for the domestic corporate bond market as a larger share of savings got channelized to the capital market and favourable supply conditions had emerged because of the mounting pressure of non-performing assets in banks. The services and financial sectors were excluded as they require a different rating framework.

The debt securities of manufacturing companies whose rating categories remained unchanged for five years (from 2012-13 to 2016-17), accounting for 383 rating data of companies in different rating classes (AAA, AA, A, B and D), were included in the sample. The financial and rating data were collected from the Centre for Monitoring Indian Economy database. The industry data, namely, IIP for all the major industries were obtained from government website (Open Government Data, 2018). The 383 rating data from 2012-13 to 2016-17 were used for developing and improving the model. The 2017-18 data were used to check the robustness of the model with a sample of 72 rating data.

\section{B. Dependent Variable: Credit Rating Class}

The dependent variable was the rating class of the debt securities issued by listed Indian manufacturing companies. Normally, the CRAs gives symbols such as $\mathrm{AAA}, \mathrm{AA}, \mathrm{A}, \mathrm{BBB}, \mathrm{BB}, \mathrm{B}, \mathrm{C}$ and $\mathrm{D}$ (Highest safety to lowest safety) for long term debt securities. The financial data of the companies having AAA, AA and A (investment grade) rated securities were easily available whereas those of BBB, BB, 
B, C and D were not available for many companies. Hence, BBB (being investment grade category) was clubbed with A category, and BB, B and C were clubbed into the B category.

\section{Predictor Variables}

In line with the global rating agency (Moody, 2000), five financial dimensions were identified, namely, profitability, leverage, liquidity, activity and growth ratios. Financial ratios that measured the above dimensions were determined and predictor variables were chosen based on popular literature and their relevance to credit risk measurement. The IIP as a measure of industry performance was included as a variable in the model. The rating agencies use industry performance as an important determinant of rating (Moody, 2000). Size of the industry and its growth prospects were an important criteria in the assessment of rating. The IIP is an index which shows growth rates of different industry groups in India which are computed and published by Central Statistical Organisation in India. Table 1 presents all the variables included in the new credit risk model.

Table 1.

\section{Variables Included in the New Model for Credit Risk}

This table includes details on variables. Column 1 has names of variables while column 2 contains full definition of each variable. Variables are chosen based on popular literature.

\begin{tabular}{|c|c|}
\hline Variables & Definition \\
\hline \multicolumn{2}{|l|}{ Dependent Variable } \\
\hline Credit Rating Class (CRC) & $\begin{array}{l}\text { Following five rating categories AAA, AA, A, B and D are included as } \\
\text { ordinal variable. }\end{array}$ \\
\hline \multicolumn{2}{|l|}{ Predictor Variables } \\
\hline Government (Gov) & $\begin{array}{l}\text { Ownership variable is a dummy with ' } 1 \text { ' if the company is government } \\
\text { owned and ' } 0 \text { ' if the company is non-government owned. }\end{array}$ \\
\hline $\begin{array}{l}\text { Natural Logarithm of Total } \\
\text { Assets (lnTA) }\end{array}$ & $\begin{array}{c}\text { Size is negatively correlated to financial distress and Total Assets } \\
\text { is included as a size variable. Logarithm transformation is done to } \\
\text { normalize it (Deakin, 1972). }\end{array}$ \\
\hline $\begin{array}{l}\text { Retained earnings / Total Assets } \\
\text { (RETA) }\end{array}$ & $\begin{array}{c}\text { This is the measure of cumulative profitability and implicitly considers } \\
\text { the age of the firm (Altman, 1968). }\end{array}$ \\
\hline $\begin{array}{l}\text { Book Value of Equity / Total Debt } \\
\text { (BVETD) }\end{array}$ & $\begin{array}{c}\text { This solvency ratio is one of the important indicator of credit risk } \\
\text { (Altman, 1968) }\end{array}$ \\
\hline Cash / Total Assets (CTA) & $\begin{array}{c}\text { This liquidity measure shows better discriminatory power in predicting } \\
\text { financial distress (Deakin, 1972). }\end{array}$ \\
\hline Sales Growth (SG) & $\begin{array}{l}\text { Growth in sales is symptomatic of a high risk (Barboza, Kimura, \& } \\
\text { Altman, 2017). Sales growth over two years is included in the model. }\end{array}$ \\
\hline Beta & $\begin{array}{l}\text { This is useful aggregation of the firms operational and financial risk } \\
\text { characteristics (Brooks, Ingram, \& Copeland, 1983). }\end{array}$ \\
\hline $\begin{array}{l}\text { Earnings Before Interest and Tax/ } \\
\text { Interest (DSCR) }\end{array}$ & $\begin{array}{l}\text { This measure is an important determinant of debt repaying capacity of } \\
\text { the firm and predictor of credit risk (Altman, Haldeman, \& } \mathrm{P}, 1977) \text {. }\end{array}$ \\
\hline $\begin{array}{l}\text { Index of Industrial Production } \\
\text { (IIP) }\end{array}$ & $\begin{array}{c}\text { The sample companies were categorized into major industries and its } \\
\text { Index of Industrial production were included as a variable. Apart from } \\
\text { financial ratios, industry variable is considered as predictor of credit } \\
\text { risk ( Pogue \& Soldofsky., 1969). }\end{array}$ \\
\hline
\end{tabular}




\section{Descriptive Statistics}

Table 2 shows descriptive statistics for the rating categories such as AAA, AA, A, B and D. A key feature of the data is that there is greater variability in debt servicing capacity ratio (DSCR) of the companies. This is due to the fact that certain companies in the investment grade have less debt with superior repaying capacity. All the other variables show less variability as it is evident from mean, median and standard deviation values. Most of the companies in category D have negative retained earnings which was the result of the accumulated losses. This resulted in negative mean retained earnings/total assets for that category.

Table 2.

\section{Descriptive Statistics}

This table reports the minimum, $1^{\text {st }}$ quartile, median, mean, $3^{\text {rd }}$ quartile, maximum value and standard deviation of the predictor variables; $\ln T A$ is logarithm of total assets, RETA is retained earnings to total assets, BVETD is book value of equity to total debt, OITA is operating income to total assets, WCTA is working capital to total assets, CTA is cash to total assets, $S G$ is sales growth over two years, Beta is systematic risk of the firm equity, DSCR is debt service coverage ratio, and IIP is index of industrial production. Results are computed from RStudio Version 1.1.453.

\begin{tabular}{|c|c|c|c|c|c|c|c|c|c|c|}
\hline \multicolumn{11}{|c|}{ Panel A: Full Sample } \\
\hline & $\ln T A$ & RETA & BVETD & OITA & WCTA & $C T A$ & $S G$ & BETA & DSCR & IIP \\
\hline Min & 1.37 & -4.66 & -0.66 & -0.68 & -3.27 & -0.26 & -0.98 & 0.00 & -100.4 & 9.49 \\
\hline $1 \mathrm{stQu}$ & 3.23 & 0.030 & 0.415 & 0.04 & -0.06 & 0.01 & -0.06 & 0.85 & 1.03 & 22.85 \\
\hline Median & 3.7 & 0.130 & 0.8 & 0.07 & 0.05 & 0.01 & 0.09 & 1.09 & 2.42 & 29.32 \\
\hline Mean & 3.72 & 0.097 & 0.96 & 0.094 & 0.013 & 0.038 & 0.14 & 1.19 & 58.95 & 30.00 \\
\hline 3rdQu & 4.19 & 0.285 & 1.295 & 0.11 & 0.14 & 0.03 & 0.26 & 1.49 & 6.355 & 37.15 \\
\hline Max & 5.74 & 5.72 & 5.91 & 8.14 & 2.35 & 0.51 & 13.83 & 3.31 & 15372 & 76.06 \\
\hline S.D & 0.88 & 0.54 & 0.83 & 0.44 & 0.34 & 0.05 & 0.80 & 0.52 & 794.55 & 11.08 \\
\hline \multicolumn{11}{|c|}{ Panel B: Rating Category AAA } \\
\hline Min & 3.31 & -0.19 & 0.14 & -0.09 & -0.21 & 0 & -0.47 & 0.68 & -2.62 & 20.51 \\
\hline 1stQu & 3.94 & 0.05 & 0.65 & 0.08 & -0.02 & 0.01 & -0.02 & 0.78 & 4.28 & 29.05 \\
\hline Median & 4.70 & 0.18 & 1.1 & 0.11 & 0.08 & 0.02 & 0.13 & 1.04 & 9.66 & 36.62 \\
\hline Mean & 4.47 & 0.25 & 1.23 & 0.15 & 0.09 & 0.06 & 0.13 & 1.04 & 286.73 & 35.8 \\
\hline 3rdQu & 4.89 & 0.475 & 1.81 & 0.18 & 0.17 & 0.1 & 0.27 & 1.29 & 18.16 & 37.4 \\
\hline Max & 5.74 & 0.65 & 3.54 & 1.78 & 0.62 & 0.26 & 0.93 & 1.46 & 15372 & 76.06 \\
\hline S.D & 0.68 & 0.23 & 0.75 & 0.21 & 0.14 & 0.06 & 0.24 & 0.26 & 1786.75 & 12.43 \\
\hline \multicolumn{11}{|c|}{ Panel C: Rating Category AA } \\
\hline Min & 2.61 & -0.08 & 0.41 & -0.08 & -0.57 & 0 & -0.71 & 0.6 & -5.24 & 13.27 \\
\hline 1stQu & 3.29 & 0.09 & 0.775 & 0.06 & -0.04 & 0.01 & 0.05 & 0.77 & 2.81 & 22.07 \\
\hline Median & 3.69 & 0.23 & 1.11 & 0.09 & 0.06 & 0.02 & 0.17 & 1.00 & 4.91 & 28.83 \\
\hline Mean & 3.84 & 0.22 & 1.29 & 0.09 & 0.06 & 0.03 & 0.32 & 1.11 & 6.97 & 29.3 \\
\hline 3rdQu & 4.69 & 0.325 & 1.49 & 0.12 & 0.14 & 0.04 & 0.33 & 1.46 & 7.95 & 37.4 \\
\hline Max & 5.28 & 0.57 & 4.35 & 0.24 & 0.51 & 0.22 & 13.83 & 1.88 & 58.86 & 57.43 \\
\hline S.D & 0.76 & 0.14 & 0.68 & 0.06 & 0.16 & 0.04 & 1.27 & 0.38 & 8.07 & 11.01 \\
\hline \multicolumn{11}{|c|}{ Panel D: Rating Category A } \\
\hline Min & 2.37 & -3.16 & -0.66 & -0.68 & -2.01 & 0 & -0.78 & 0.81 & -3.61 & 13.27 \\
\hline 1stQu & 3.23 & 0.01 & 0.48 & 0.025 & -0.06 & 0 & -0.065 & 0.99 & 0.68 & 22.19 \\
\hline Median & 3.58 & 0.08 & 0.7 & 0.055 & 0.04 & 0.01 & 0.08 & 1.48 & 1.67 & 24.29 \\
\hline Mean & 3.58 & 0.038 & 0.85 & 0.027 & -0.04 & 0.02 & 0.12 & 1.40 & 1.66 & 29.38 \\
\hline
\end{tabular}


Table 2.

Descriptive Statistics (Continued)

\begin{tabular}{lcccccccccc}
\hline \multicolumn{10}{c}{ Panel D: Rating Category A } \\
\hline & lnTA & RETA & BVETD & OITA & WCTA & CTA & SG & BETA & DSCR & IIP \\
\hline 3rdQu & 3.89 & 0.17 & 0.95 & 0.08 & 0.11 & 0.02 & 0.21 & 1.67 & 2.405 & 37.95 \\
Max & 4.89 & 0.39 & 4.8 & 0.17 & 0.39 & 0.24 & 1.74 & 2.29 & 10.61 & 57.43 \\
S.D & 0.67 & 0.37 & 0.82 & 0.11 & 0.28 & 0.04 & 0.31 & 0.43 & 7.27 & 10.90 \\
\hline \multicolumn{8}{c}{ Panel E: Rating Category B } \\
\hline Min & 1.37 & -0.09 & -0.05 & -0.22 & -0.18 & 0.00 & -0.73 & 0.00 & -21.07 & 9.49 \\
1stQu & 2.68 & 0.04 & 0.2 & 0.03 & -0.06 & 0.01 & -0.07 & 0.71 & 0.71 & 23.4 \\
Median & 2.82 & 0.13 & 0.5 & 0.05 & 0.09 & 0.01 & 0 & 1.34 & 1.11 & 25.75 \\
Mean & 2.97 & 0.13 & 0.79 & 0.23 & 0.07 & 0.03 & 0.035 & 1.13 & 5.19 & 27.88 \\
3rdQu & 3.78 & 0.18 & 0.94 & 0.09 & 0.16 & 0.02 & 0.13 & 1.56 & 1.61 & 36.87 \\
Max & 4.22 & 0.56 & 5.91 & 8.14 & 0.35 & 0.18 & 0.85 & 1.80 & 224.32 & 40.89 \\
S.D & 0.77 & 0.13 & 0.98 & 0.91 & 0.29 & 0.04 & 0.33 & 0.54 & 25.25 & 9.93 \\
\hline \multicolumn{8}{c}{ Panel F: Rating Category D } & & & \\
\hline Min & 2.01 & -4.66 & -0.66 & -0.68 & -3.27 & -0.26 & -0.98 & 0.53 & -100.4 & 13.27 \\
1stQu & 2.63 & -0.68 & -0.10 & -0.07 & -0.34 & 0.00 & -0.51 & 0.78 & -1.68 & 21.61 \\
Median & 3.43 & -0.20 & 0.14 & 0.02 & -0.04 & 0.01 & -0.21 & 1.02 & 0.11 & 24.33 \\
Mean & 3.25 & -0.34 & 0.15 & 0.01 & -0.17 & 0.02 & -0.15 & 1.37 & -3.19 & 26.45 \\
3rdQu & 3.78 & 0.05 & 0.32 & 0.07 & 0.105 & 0.02 & 0.09 & 1.72 & 1.03 & 32.03 \\
Max & 4.78 & 5.72 & 1.85 & 1.42 & 2.35 & 0.51 & 1.66 & 3.31 & 13.41 & 40.89 \\
S.D & 0.91 & 1.16 & 0.42 & 0.25 & 0.70 & 0.08 & 0.53 & 0.90 & 15.44 & 8.28 \\
\hline
\end{tabular}

E. Credit Risk Models using Ordinal Logistic Regression

Table 3 presents models used in the study which include our model and the three classical credit risk models. Table 4 shows the results of the OLR for all the credit risk models. In James-Horrigan model, the rating class is significantly influenced by (a) $\ln \mathrm{TA}$ at the $1 \%$ level of significance (LOS), (b) BVETD at the $1 \%$ LOS and (c) SNW at the 5\% LOS. In the Kaplan-Urwitz model, the rating class is significantly influenced by (a) $\ln$ TA, beta and DSCR at the $0.1 \%$ LOS and (b) the NITA at the $10 \%$ LOS. In EMS model, rating class is significantly influenced by RETA at the $5 \%$ LOS and negatively influenced by BVETD at $0.1 \%$ LOS.

In our model, rating class is (a) positively and significantly influenced by beta at the $0.1 \%$ and RETA at the 1\% LOS; and (b) negatively and significantly influenced by Gov, InTA, BVETD, CTA and DSCR at the $0.1 \%$ LOS. The high rating class is given to securities of companies which are government owned, larger in size, low levered and with low systematic risk. Companies with higher debt service coverage ratio and higher liquidity are not given higher rating which may be attributed to inefficient cash management such as more accounting profits (less cash flow) and high cash holding (reduces the profitability). 
Table 3.

\section{Models Used in the Study}

This table presents the classic credit risk models and new credit risk model. JH is the James-Horrigan model, KU is the Kaplan-Urwitz model, EMS is the emerging market score model,, CRC is credit rating class, $\ln T A$ is $\log$ arithm of total assets, BVETD is book value of equity to total debt, SNW is sales to net worth, OIS is operating income to sales, WCS is working capital to sales, LLTA is long-term liability to total assets, NITA is net income to total assets, DSCR is debt service coverage ratio, OITA is operating income to total assets, WCTA is working capital to total assets, RETA is retained earnings to total assets, CTA is cash to total assets, $S G$ is sales growth over two years, Beta is systematic risk of the firm equity, IIP is index of industrial production, and Gov is the ownership variable, ' 1 ' indicates government owned and ' 0 ' indicates non- government owned enterprise.

\begin{tabular}{lc}
\hline & Existing prediction models \\
\hline $\mathrm{JH}$ & $\mathrm{CRC}=\beta_{0}+\beta_{1} \operatorname{lnTA}+\beta_{2}$ BVETD $+\beta_{3}$ SNW $+\beta_{4}$ OIS $+\beta_{5}$ WCS $+\varepsilon_{\mathrm{i}}$ \\
$\mathrm{KU}$ & $\mathrm{CRC}=\beta_{0}+\beta_{1}$ lnTA $+\beta_{2}$ LLTA $+\beta_{3}$ NITA $+\beta_{4}$ Beta $+\beta_{5}$ DSCR $+\varepsilon_{\mathrm{i}}$ \\
EMS & $\mathrm{CRC}=\beta_{0}+\beta_{1}$ OITA $+\beta_{2}$ WCTA $+\beta_{3}$ RETA $+\beta_{4}$ BVETD $+\varepsilon_{\mathrm{i}}$ \\
\hline \multicolumn{2}{c}{ New Prediction model } \\
mow & CRC $=\beta_{0}+\beta_{1}$ Gov $+\beta_{2}$ lnTA $+\beta_{3}$ RETA $+\beta_{4}$ BVETD $+\beta_{5}$ CTA $+\beta_{6}$ SG $+\beta_{7}$ Beta + \\
\hline
\end{tabular}

Table 4.

\section{Ordinal Logistic Regression Results - Credit Risk Models}

This table presents the results of Ordinal Logistic Regression of various credit risk models: JH is James-Horrigan model, KU is Kaplan-Urwitz model, EMS is Emerging Market Score model. Gov is the ownership variable, ' 1 ' indicates government owned and ' 0 ' indicates non-government owned enterprise. $\ln T A$ is logarithm of total assets, RETA is retained earnings to total assets, BVETD is book value of equity to total debt, LLTA is long-term liability to total assets, SNW is sales to net worth, NITA is net income to total assets, OITA is operating income to total assets, OIS is operating income to sales, WCTA is working capital to total assets, WCS is working capital to sales, CTA is cash to total assets, $S G$ is sales growth over two years, Beta is systematic risk of the firm equity , DSCR is debt service coverage ratio, IIP

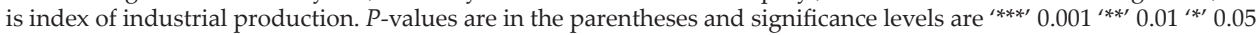
“." 0.1. Results computed from RStudio Version 1.1.453.

\begin{tabular}{lcccc}
\hline Variables & JH & KU & EMS & New model \\
\hline Gov & & & & -20.308 \\
InTA & -1.6436 & -1.8347 & & $\left(0.0000^{* * *}\right)$ \\
RETA & $\left(0.0000^{* * *}\right)$ & $\left(0.0000^{* * *}\right)$ & & -1.785 \\
BVETD & & & 0.5472 & $\left(0.0000^{* * *}\right)$ \\
LLTA & -1.38366 & & $\left(0.0155^{*}\right)$ & $(0.744$ \\
SNW & $\left(0.0000^{* *}\right)$ & & -0.859 & -1.296 \\
& & -0.5253 & $\left(0.0000^{* * *}\right)$ & $\left(0.0000^{* * *}\right)$ \\
NITA & -0.1108 & & \\
OITA & -0.07194 & & & \\
OIS & $\left(0.0020^{*}\right)$ & & & \\
WCTA & & -0.6686 & & \\
\hline
\end{tabular}


Table 4.

Ordinal Logistic Regression Results - Credit Risk Models (Continued)

\begin{tabular}{|c|c|c|c|c|}
\hline Variables & $\mathrm{JH}$ & KU & EMS & New model \\
\hline WCS & $\begin{array}{c}-0.01405 \\
(0.6247)\end{array}$ & & & \\
\hline CTA & & & & $\begin{array}{c}-16.849 \\
\left(0.0000^{* * *}\right)\end{array}$ \\
\hline$S G$ & & & & $\begin{array}{c}-0.238 \\
(0.0790 .)\end{array}$ \\
\hline Beta & & $\begin{array}{c}1.6658 \\
\left(0.0000^{* * *}\right)\end{array}$ & & $\begin{array}{c}1.047 \\
\left(0.0000^{* * *}\right)\end{array}$ \\
\hline$D S C R$ & & $\begin{array}{c}-0.1744 \\
\left(0.0000^{* * *}\right)\end{array}$ & & $\begin{array}{c}-0.0794 \\
\left(0.0000^{* * *}\right)\end{array}$ \\
\hline IIP & & & & $\begin{array}{c}-0.024 \\
\left(0.0418^{*}\right)\end{array}$ \\
\hline Deviance & 754.0407 & 576.4323 & 753.2399 & 460.9017 \\
\hline AIC & 770.0407 & 594.4323 & 769.2399 & 486.9017 \\
\hline Log Likelihood & -377.0203 & -288.2162 & -375.9200 & -230.4508 \\
\hline Pseudo R2 - McFadden & 0.0941 & 0.2922 & 0.0948 & 0.4182 \\
\hline $\begin{array}{l}\text { Pseudo R2 - } \\
\text { Cox and Snell }\end{array}$ & 0.1863 & 0.2922 & 0.1873 & 0.5843 \\
\hline $\begin{array}{l}\text { Pseudo R2 - } \\
\text { Nagelkerke }\end{array}$ & 0.2097 & 0.5272 & 0.2110 & 0.6805 \\
\hline
\end{tabular}

In our model, all the nine variables chosen are significantly influencing the rating class. Efficiency of the model is assessed through comparison with related models. The smaller the deviance and AIC, the better is the fit of the model. The AIC helps to avoid overfitting by penalizing addition of more variables to the model. Deviance and AIC are the smallest for our model. Log likelihood (i.e., the log of the likelihood) will be always negative, with higher values (closer to zero) indicating a better model and it can be seen that our model has statistics closest to zero than other models. The Pseudo- $R^{2}$ values are better for our model compared to the other models. It is found that deviance, $\mathrm{AIC}$, log-likelihood and pseudo- $R^{2}$ values are better for our model. All the measures show that our model is better than other classical models.

Figure 1 shows the VIF and eigenvalues plot of our model. Imdadullah, Aslam and Altaf (2016) have presented commonly used threshold values for VIF and eigenvalues. Multicollinearity diagnostics suggest an upper threshold of 10 for the VIF values and the lower threshold of 0.01 for the eigenvalues. As VIF values are less than the threshold of 10 and eigenvalues are above the threshold of 0.01 , it suggests that there is no multicollinearity among regressors. 
Figure 1.

\section{VIF and Eigenvalues Plot}

This figure illustrates Variance Inflation Factor (VIF) and eigenvalues of the predictor variables used in the the model. The VIF values for the individual predictor variables are presented in the VIF plot; and EV1 to EV9 are the eigenvalues calculated for nine predictor variables used in new ordinal regression model.

VIF Plot

\section{VIF Values}

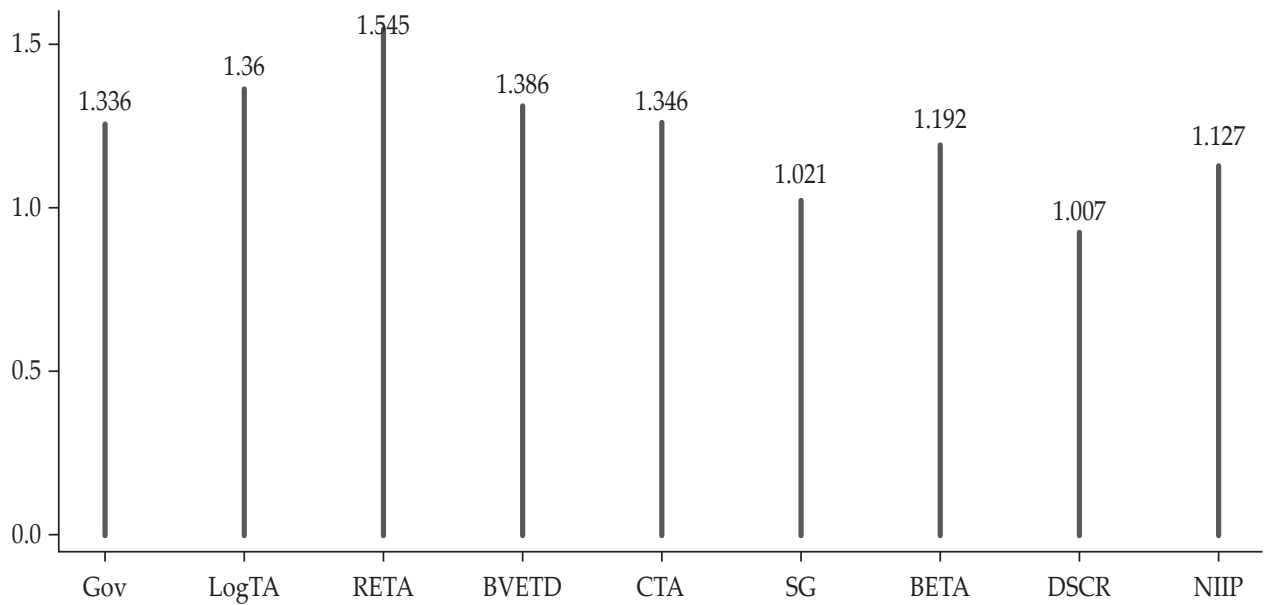

Eigenvalues

Eigenvalues Plot

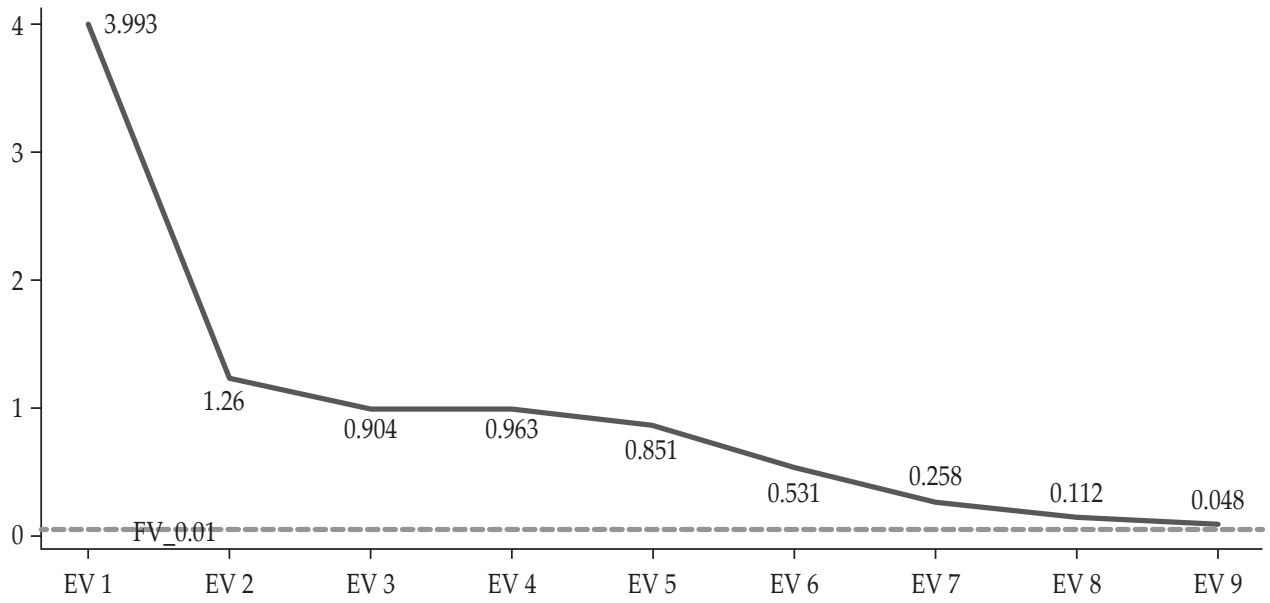

\section{F. Refining our model using ML techniques}

Table 5 shows the performance metrics of our model using ANN, SVM and RF. In case of ANN, it is found that the accuracy rate is greater than $85 \%$ for all rating categories such as AAA, AA, A, B and D. Sensitivity of ANN is lower for $B$ category as False Negative is more for that category. Specificity is higher since False Positives are lower for all the rating categories. The F-score is greater than $80 \%$ for AAA, AA and D category. For SVM and RF, it is found that accuracy 
and the F-score are greater than $90 \%$, particularly RF shows greater accuracy than SVM. Sensitivity and specificity of SVM and RF is higher than ANN. Overall, RF shows superior results than ANN and SVM.

Table 5.

\section{Performance Metrics for Each Rating Category of the New Credit Risk Model Using ANN, SVM and RF}

Results reported in this table are computed based on the confusion matrix and shows the performance metrics of ANN, SVM and RF. TP is True Positive, TN is True Negative, FP is False Positive, FN is False Negative, AR is Accuracy Rate, F-S is F-score $(\%)$, Sen is Sensitivity, Spe is Specificity ${ }^{*}$ Accuracy rate $=(\mathrm{TP}+\mathrm{TN}) /(\mathrm{TP}+\mathrm{TN}+\mathrm{FP}+\mathrm{FN})$, ${ }^{*} F$-Score $=2^{*} \mathrm{TP} /\left(2^{*} \mathrm{TP}+\mathrm{FP}+\mathrm{FN}\right),{ }^{*}$ Sensitivity $=\mathrm{TP} /(\mathrm{TP}+\mathrm{FN}),{ }^{*}$ Specificity $=\mathrm{TN} /(\mathrm{TN}+\mathrm{FP})$.

\begin{tabular}{|c|c|c|c|c|c|c|c|c|c|c|}
\hline Metric & \multicolumn{2}{|c|}{ AAA } & \multicolumn{2}{|c|}{ AA } & \multicolumn{2}{|c|}{ A } & \multicolumn{2}{|c|}{ B } & \multicolumn{2}{|c|}{ D } \\
\hline $\begin{array}{l}\text { Sample } \\
\text { Set }\end{array}$ & \multicolumn{2}{|c|}{ Train Test } & \multicolumn{2}{|c|}{ Train Test } & \multicolumn{2}{|c|}{ Train Test } & \multicolumn{2}{|c|}{ Train Test } & \multicolumn{2}{|c|}{ Train Test } \\
\hline \multicolumn{11}{|c|}{ Performance metrics for each rating category of new credit risk model using ANN } \\
\hline $\mathrm{TP}$ & 55 & 12 & 80 & 24 & 58 & 9 & 23 & 7 & 38 & 10 \\
\hline $\mathrm{TN}$ & 199 & 50 & 174 & 38 & 196 & 53 & 231 & 55 & 216 & 52 \\
\hline FP & 6 & 1 & 11 & 6 & 22 & 5 & 11 & 2 & 2 & 1 \\
\hline FN & 5 & 3 & 20 & 3 & 10 & 3 & 10 & 5 & 7 & 1 \\
\hline $\operatorname{AR}(\%) *$ & 95.85 & 93.94 & 89.12 & 87.32 & 88.81 & 88.57 & 92.36 & 89.86 & 96.58 & 96.88 \\
\hline F-S $(\%) *$ & 90.91 & 85.71 & 83.77 & 84.21 & 78.38 & 69.23 & 68.66 & 66.67 & 89.41 & 90.91 \\
\hline Sen $(\%)^{*}$ & 91.67 & 80.00 & 80.00 & 88.89 & 85.29 & 75.00 & 69.70 & 58.33 & 84.44 & 90.91 \\
\hline Spe $(\%)^{*}$ & 97.07 & 98.04 & 94.05 & 86.36 & 89.91 & 91.38 & 95.45 & 96.49 & 99.08 & 98.11 \\
\hline \multicolumn{11}{|c|}{ Performance metrics for each rating category of new credit risk model using SVM } \\
\hline TP & 61 & 14 & 95 & 28 & 60 & 17 & 37 & 6 & 46 & 6 \\
\hline $\mathrm{TN}$ & 238 & 57 & 204 & 43 & 239 & 54 & 262 & 65 & 253 & 65 \\
\hline FP & 0 & 0 & 4 & 0 & 0 & 3 & 2 & 0 & 1 & 3 \\
\hline FN & 1 & 0 & 2 & 3 & 2 & 3 & 2 & 0 & 0 & 0 \\
\hline $\operatorname{AR}(\%) *$ & 99.67 & 100 & 98.03 & 95.95 & 99.34 & 92.21 & 98.68 & 100 & 99.67 & 95.95 \\
\hline F-S $(\%) *$ & 99.19 & 100 & 96.94 & 94.92 & 98.36 & 85.00 & 94.87 & 100 & 98.92 & 80.00 \\
\hline Sen $(\%)^{*}$ & 98.39 & 100 & 97.94 & 90.32 & 96.77 & 85.00 & 94.87 & 100 & 100 & 100 \\
\hline Spe $(\%)^{*}$ & 100 & 100 & 98.08 & 100 & 100 & 94.74 & 99.24 & 100 & 99.61 & 95.59 \\
\hline \multicolumn{11}{|c|}{ Performance metric for each rating category of new credit risk model using RF } \\
\hline $\mathrm{TP}$ & 60 & 15 & 101 & 25 & 63 & 14 & 38 & 7 & 44 & 11 \\
\hline $\mathrm{TN}$ & 246 & 57 & 205 & 47 & 243 & 58 & 268 & 65 & 262 & 61 \\
\hline FP & 0 & 0 & 0 & 1 & 0 & 3 & 0 & 0 & 0 & 1 \\
\hline FN & 0 & 0 & 0 & 1 & 0 & 0 & 0 & 2 & 0 & 2 \\
\hline $\operatorname{AR}(\%) *$ & 100 & 100 & 100 & 97.30 & 100 & 96.00 & 100 & 97.30 & 100 & 96.00 \\
\hline F-S $(\%)^{*}$ & 100 & 100 & 100 & 96.15 & 100 & 90.32 & 100 & 87.50 & 100 & 88.00 \\
\hline Sen $(\%)^{*}$ & 100 & 100 & 100 & 96.15 & 100 & 100.00 & 100 & 77.78 & 100 & 84.62 \\
\hline Spe $(\%)^{*}$ & 100 & 100 & 100 & 97.92 & 100 & 95.08 & 100 & 100.00 & 100 & 98.39 \\
\hline
\end{tabular}




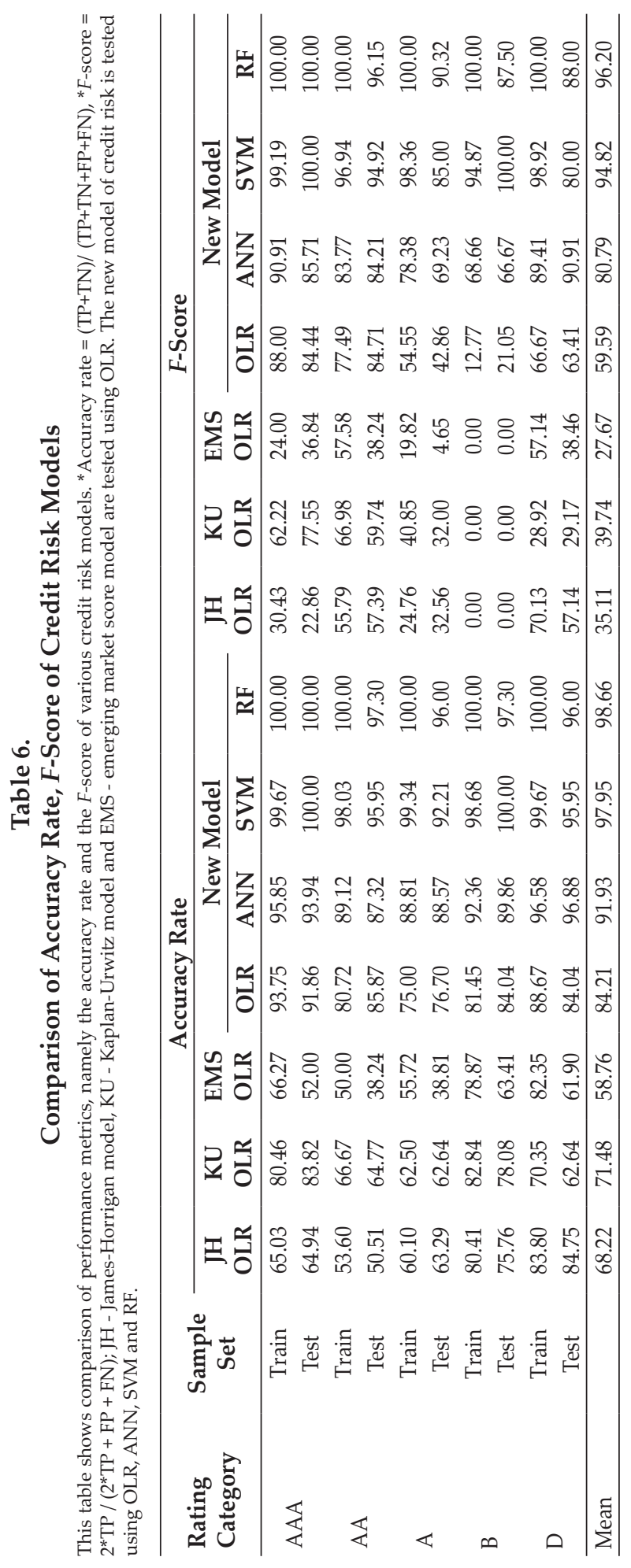




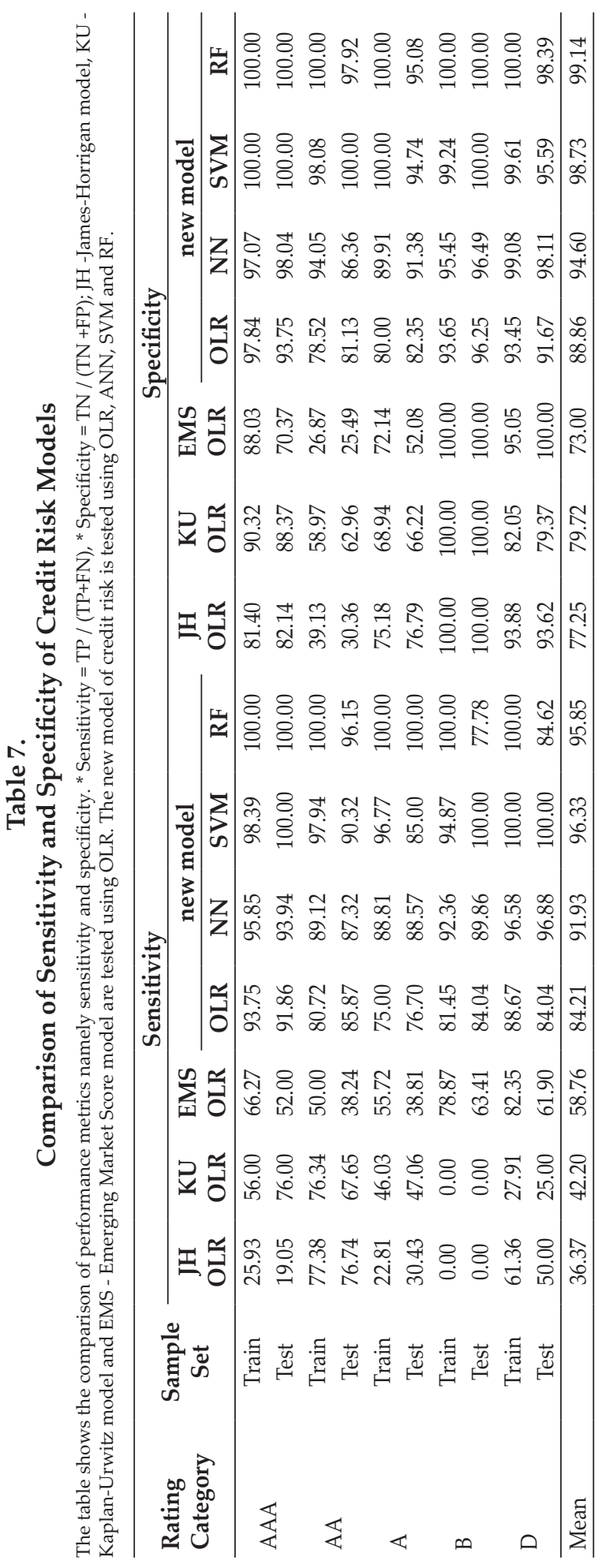


From Table 6, it is found that among the classical models, Kaplan-Urwitz model shows better accuracy. Our model shows better accuracy and predictive ability than the existing classical models in all rating categories. The OLR model shows less accuracy for A category than other categories. The F-score is another measure of predictive ability and higher the $F$-score the better is the predictive power of the model. A score of 1 means the model is perfect. Lowest possible F-score is 0 . The F-score shows lesser accuracy for A and B categories when compared to other categories. This may be due to non-availability of data for those categories. The use of ANN, SVM and RF gives superior accuracy rate across all rating categories for our model. Among the ML techniques, it is found that SVM and RF show better results in terms of accuracy rate and $F$-score. We have not shown the implementation of classical models in ML techniques since their prediction accuracy is lower than its OLR model. All the classical models showed lower accuracy since number of variables were reduced and had lower sensitivity and specificity, consistent with the study of Barboza, Kimura, \& Altman (2017). To our knowledge, there had been no studies on credit risk model using ML and many studies were available in default prediction. In our study, ML techniques showed superior accuracy than traditional statistical methods like OLR which were consistent with earlier studies (Back, Laitinen, \& Sere, 1996; Huang, Chen, Hsua, Chen, \& Wu, 2004; Ibourk \& Aazzab, 2016; Barboza, Kimura, \& Altman, 2017). It was found that prediction accuracy was above $90 \%$ in the case of SVM and RF which was comparable with many default studies involving ML methods (Yim \& Mitchell, 2005; Wang, Mac, \& Yang, 2014; Iturriaga \& Sanz, 2015; Barboza, Kimura, \& Altman, 2017).

From Table 7, it is found that our model has better sensitivity and specificity than other rating prediction models. As the accuracy rate does not give the complete picture, it is considered with sensitivity (Type-II error) and specificity (Type-I error). Sensitivity is the metric that evaluates a model's ability to predict true positives of each available category (Mitrani, 2019). Specificity is the metric that evaluates a model's ability to predict true negatives of each available category. Model with better predictive ability will have higher sensitivity and specificity. As a superior model, our model has both high sensitivity and specificity. Among the ML techniques, SVM and RF shows superior results than ANN.

Table 8.

Descriptive Statistics - New Sample

The table shows the descriptive statistics which include minimum, 1st quartile, median, mean, 3rd quartile, maximum and standard deviation of the new sample of rating data of year 2017-18.

\begin{tabular}{lccccccccc}
\hline & InTA & RETA & BVETD & OITA & WCTA & CTA & SG & BETA & DSCR \\
\hline Min & 1.35 & 2.56 & 0.68 & 2.12 & 2.53 & 0.00 & 1.00 & 0.32 & -117.60 \\
1st Qu. & 2.70 & 0.02 & 0.30 & 0.05 & 0.07 & 0.00 & 0.03 & 0.57 & 1.12 \\
Median & 3.30 & 0.09 & 0.60 & 0.08 & 0.10 & 0.01 & 0.11 & 1.00 & 1.80 \\
Mean & 3.35 & 0.04 & 0.94 & 0.03 & 0.01 & 0.04 & 0.11 & 0.97 & 235.98 \\
3rd Qu. & 4.04 & 0.21 & 1.03 & 0.12 & 0.19 & 0.03 & 0.29 & 1.54 & 6.02 \\
Max & 5.46 & 0.77 & 7.04 & 0.26 & 0.95 & 0.64 & 1.78 & 2.48 & 15397 \\
SD & 0.91 & 1.16 & 0.42 & 0.25 & 0.70 & 0.08 & 0.53 & 0.90 & 15.44 \\
\hline
\end{tabular}




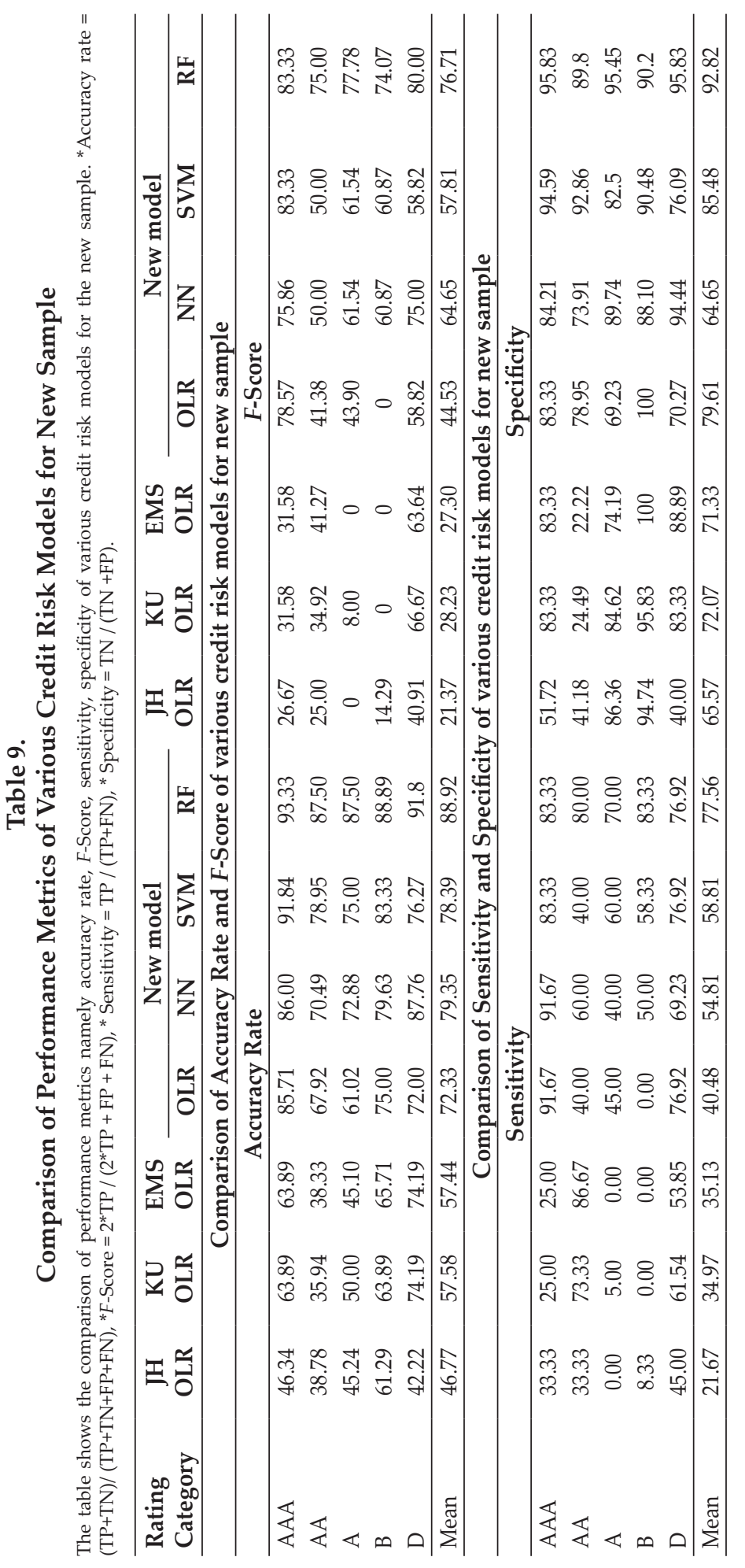


Table 8 shows descriptive statistics of the new sample of rating data for 201718 for stress testing the models. From Table 9, it is found that the accuracy rate of our model using OLR is able to predict above $70 \%$ in all instances. The ML implementation shows better accuracy rate, particularly the RF method is able to predict around $90 \%$ of instances. With the F-score also, RF shows better predictive ability and improved performance than the basic techniques. It is inferred that credit risk models shows better specificity than sensitivity which means that false positive was lesser when compared with false negative. Among the ML techniques, RF shows superior sensitivity and specificity than other techniques.

\section{CONCLUSION}

The prediction accuracy of our model is better than the existing rating prediction models. Our model when trained using ANN showed improved prediction accuracy. Advanced ML techniques, such as SVM and RF, have improved the performance metrics of our model in terms of the accuracy rate, F-score, sensitivity and specificity. This model can be a useful tool for users of the rating to perform due diligence on their own by using publicly available information. Regulators can also use this model for their supervisory function. Investors, depositors and other participants in the capital markets can evaluate the credit risk profile of their investment and consequently define their ideal risk-return combination.

This study has the following limitations: Macroeconomic and corporate governance variables also influence credit risk which when included as predictors would improve the overall accuracy of the model. Second, non-availability of rating data for some categories such as $\mathrm{BBB}, \mathrm{BB}$ and $\mathrm{C}$ was also a limiting factor.

There is scope for further research. The Asian credit rating model can be developed using other emerging economies data. Also, increasing the firm year observations can provide better results when ML techniques are used. In stressful times, like Covid-19 pandemic (see Sha and Sharma, 2020; Sharma and Sha, 2020), measurement of credit risk is very important and incorporating new pandemic related data points will make the credit risk model more robust and valid. In our study, the best predictive model was selected using trial and error method by training the model through many iterations. However, usage of optimization algorithms would improve selection of the best model. Development of the model can be done for other securities such as short term debt instruments, fixed deposits and structured instruments. A similar model can be also be developed for financial institutions separately. Further, feature selection method could improve the selection of predictor variables.

The outcome of study reveals that complex computational machine learning techniques do improve the credit risk classification. Fund managers and other users can deploy the machine learning models which would help them to lower their credit risk exposure and achieve better profitability than before.

\section{Acknowledgement}

The authors are grateful to the Managing Editor, Prof. Paresh Narayan, for handling our paper and helpful comments and suggestions from two reviewers of this journal are highly appreciated. The usual disclaimer applies. 


\section{REFERENCES}

Agresti, A. (2002). Categorical Data Analysis (2nd ed.). USA: Wiley Series in Probability and Statistics.

Alifiah, M. N., \& Tahir, M. S. (2018). Predicting Financial Distress Companies in the Manufacturing and Non-Manufacturing Sectors in Malaysia Using Macroeconomic Variables. Management Science Letters, 8, 593-604.

Altman. (1968). Financial Ratios, Discriminant Analysis and the Prediction of Corporate. Journal of Finance, 23, 589-609.

Altman. (2005). An Emerging Market Scoring System for Corporate Bonds. Emerging Markets Review, 6, 311-323. doi:10.1016/j.ememar.2005.09.007

Altman, Haldeman, R. G., \& P, N. (1977). Zeta Analysis: A New model to identify bankruptcy risk of corporations. Journal of banking and finance, 1, 29-54.

Altman, Hartzel, J., \& Peck, M. (1998). Emerging Market Corporate Bonds A Scoring System. Emerging Market Capital Flows, 2, 391-400. https://doi. org/10.1007/978-1-4615-6197-2_25

Ang, J. S., \& Patel, K. A. (1974). Bond Rating Methods: Comparison and Validation. The Journal of Finance, 30, 631-640.

Back, B., Laitinen, T., \& Sere, K. (1996). Neural Networks and Genetic Algorithms for Bankruptcy Predictions. Expert Systems with Applications, 11, 407-413. https://doi.org/10.1016/S0957-4174(96)00055-3

Bandyopadhyay, A. (2006, May). Predicting Probability of Default of Indian Corporate Bonds: Logistic and Z-Score Model Approaches. The Journal of Risk Finance, 7, 255-272. https://doi.org/0.1108/15265940610664942

Barboza, F., Kimura, H., \& Altman, E. (2017). Machine Learning Models and Bankruptcy Prediction. Expert Systems With Applications, 83, 405-417. http:// dx.doi.org/10.1016/j.eswa.2017.04.006

Basel. (2017). Basel III. Basel Committee of banking supervision. Retrieved from https:// www.bis.org/

Beaver, W. H. (1966). Financial Ratios as Predictors of Failure. Journal of Accounting Research, 4, 77-111.

Benmelech, E., \& Dlugosz, J. (2009). The Credit Rating Crisis. NBER Macroeconomics Annual, 24, 161-207.

Breiman, L. (2001). Random Forests. Machine Learning, 5-32.

Brooks, L. D., Ingram, R. W., \& Copeland, R. M. (1983). Credit Risk, Beta, and Bond Ratings. Nebraska Journal of Economics and Business, 22, 3-14.

Cortes, C., \& Vapnik, V. (1995). Support-Vector Networks. Machine Leaming, 273297.

CRISIL. (2018). CRISIL Yearbook On The Indian Debt Market. CRISIL.

D.McFadden. (1974). Conditional logit analysis of qualitative choice behavior. Frontiers in Econometrics, 105-142.

D.R.Cox, \& Snell, E. (1989). Analysis of Binary Data (2 ed.). Chapman \& Hall.

Deakin, E. B. (1972). A Discriminant Analysis of Predictors of Business Failure. Journal of Accounting Research, 10, 167 - 179.

Duvall, R. M., \& R.S.Rathinasamy. (1993). The Association of Default Risk Factors with Systematic Risk of Corporate Bonds. Journal of Economics and Finance, 17, 137-147. 
Emerson, S., Kennedy, R., O'Shea, L., \& O'Brien, J. (2019). Trends and Applications of Machine Learning in Quantitative Finance. 8th International Conference on Economics and Finance Research. Retrieved from https://ssrn.com/ abstract $=3397005$

Gante, D. D., Gerardo, B. D., \& Tanguilig, B. T. (2015). Neural Network Model Using Backpropogaton Algorithm for Credit Risk Evaluation. (pp. 12-13). Penang. Malaysia: International Conference on Artificial Intelligence and Computer Science (AICS2015).

Gentry, J., Whitford, D., \& Newbold, P. (1985). Predicting Industrial Bond Ratings with a Probit Model and Funds Flow Components. Bureau of Economic and Business Research, 46, 41-48. https://doi.org/10.2469/faj.v46.n4.41

Gerardi, K., Sherlund, S. M., Lehnert, A., \& Willen, P. (2008). Making Sense of the Subprime Crisis. Brookings Papers on Economic Activity, 69-145.

Günther, F., \& Fritsch, S. (2010). neuralnet: Training of Neural Networks. The $R$ Journal, 2.

Ho, C., \& Rao, R. P. (1993). Bond Ratings and Their Determinants in a Changing Environment. Journal of Applied Business Research, 9, 132-139. https://doi. org/10.19030/jabr.v9i1.6104

Horrigan, J. 0. (1966). The Determination of Long-Term Credit Standing With Financial Ratios. Journal of Accounting Research, 4, 44-62.

Hosmer, D. W., \& Lemeshow, S. (2000). Applied Logistic Regression (2 ed.). WileyInterscience.

Huang, Z., Chen, H., Hsua, C.-J., Chen, W.-H., \& Wu, S. (2004). Credit Rating Analysis with Support Vector Machines and Neural Networks: A Market Comparative Study. Decision Support Systems, 37, 543- 558. https://doi. org/10.1016/S0167-9236(03)00086-1

Ibourk, A., \& Aazzab, A. (2016). The Artificial Neural Networks for Classification: Case of Business Failures. Journal of Research in Business and Management, 4, 10-15.

Imdadullah, M., Aslam, M., \& Altaf, S. (2016, Dec). mctest: An R Package for Detection of Collinearity among Regressors. The R Journal, 8.

Iturriaga, F. J., \& Sanz, I. P. (2015). Bankruptcy Visualization and Prediction Using Neural Networks: A Study of U.S. Commercial Banks. Expert Systems with Applications, 42, 2857-2869. http://dx.doi.org/10.1016/j.eswa.2014.11.025

James, G., Witten, D., Hastie, T., \& Tibshirani, R. (2013). An Introduction to Statistical Learning with Applications in R. New York: Springer.

Kaplan, R. S., \& Urwitz, G. (1979, 1979). Statistical Models of Bond Ratings: A Methodological Inquiry. The Journal of Business, 52, 231-261.

Kohavi, R., \& Provost, F. (1998). Glossary of Terms. Special Issue on Applications of Machine Learning and the Knowledge Discovery Process, 30, 271-274.

Labatut, V., \& Cherifi, H. (2011). Evaluation of Performance Measures for Classifiers Comparison. Ubiquitous Computing and Communication Journal, 6, 21-34.

McCullagh., P. (1980). Regression Models for Ordinal Data. Journal of the Royal Statistical Society, 42, 109 - 142.

McCulloch, W. S., \& Pitts, W. (1943). A Logical Calculus of the Ideas Immanent in Nervous Activity. The Bulletin of Mathematical Biophysics, 5, 115-143. 
Mitrani, A. (2019). Evaluating Categorical Models II sensitivity and specificity. Toward Data Science. Retrieved from https://towardsdatascience.com/evaluatingcategoricalmodels-ii-sensitivity-and-specificity-e181e573cff8.

Moody. (2000). Risckcalc for Private Companies: Moody's Default Model. Moody's investor service.

Nagelkerke, N. J. (1991). A Note on a General Definition of the Coefficient of Determination. Biometrika, 78, 691-692.

OGD, O. G. (2018). https://data.gov.in/.

Palande, P. (2015, November 23). Amtek Auto: The Silo effect. Forbes India.

Partnoy, F. (2009, April). Rethinking Regulation of Credit Rating Agencies: An Institutional Investor Perspective. The Council of Institutional Investors.

Pillay, A. (2015, Sep). Have Rating Agencies Been Caught Napping on Corporate Debt? Livemint. Retrieved from https://www.livemint.com/Companies/ nKiB6RuSI5fXpvPVqxBr6H/Have-rating-agencies-been-caught-napping.html

Pinches, G. E., \& Mingo, K. A. (1973, March). Multivariate Analysis of Industrial Bond Rating. Journal of Finance, 28, 1-18.

Pradhan, R. (2014). Z Score Estimation for Indian Banking Sector. International Journal of Trade, Economics and Finance, 5, 516-520. https://doi.org/10.7763/ IJTEF.2014.V5.425

Pogue , T. F., \& Soldofsky., R. M. (1969). What is in a Bond Rating. Journal of Financial and Quantitative Analysis, 4, 201-228.

SEBI. (2011, June 15). Standardisation of Rating Symbols and Definitions. India.

Sharma, S.S \& Sha, Y. (2020) Part A: Special Section on COVID-19 Research. Emerging Markets Finance and Trade, 56, 3551-3553. https://doi.org/10.1080/154 0496X.2020.1858617

Sha, Y., \& Sharma, S. S. (2020). Research on Pandemics Special Issue of the Journal Emerging Markets Finance and Trade. Emerging Markets Finance and Trade, 56, 2133-2137. https://doi.or g/10.1080/1540496x.2020.1795467

Venables, W. N., \& Ripley, B. D. (2002). Modern Applied Statistics with S. Springer.

Wang, G., Mac, J., \& Yang, S. (2014). An Improved Boosting Based on Feature Selection for Corporate Bankruptcy Prediction. Expert Systems with Applications, 41, 2353 - 2361.

Yeh, C.-C., Chi, D.-J., \& Lin, Y.-R. (2014). Going-concern Prediction Using Hybrid Random Forests and Rough Set Approach. Information Sciences, 254, 98-110. https://doi.org/10.1016/j.ins.2013.07.011

Yim, J., \& Mitchell, H. (2005). A Comparison Of Corporate Distress Prediction Models in Brazil: Hybrid Neural Networks, Logit Models and Discriminant Analysis. nova Economia, 15, 73-93.

Yuan, S., \& Chu, F. (2007). Fault Diagnostics Based on Particle Swarm Optimization and Support Vector Machines. Mechanical Systems and Signal Processing, 21, 1787-1798.

Zurada, J., Foster, B. P., \& Ward, T. J. (2002). Investigation of Artificial Neural Networks for Classifying Levels of Financial Distress of Firms: The Case of an Unbalanced Training Sample. Knowledge Discovery for Business Information Systems, 600, 397-424. 
This page is intentionally left blank 